\title{
Morphological and molecular identification of Panus conchatus (Polyporaceae, Polyporales) from Yunnan Province, China
}

\author{
Luangharn $T^{1,2,3,4}$, Karunarathna $\mathrm{SC}^{1,3,4}$, Mortimer $\mathbf{P E}^{1,4^{*}}$, Hyde $\mathrm{KD}^{3,5}$ and \\ $\mathbf{X u ~ \mathbf { J } ^ { 1 , 3 , 4 * }}$
}

${ }^{1}$ Key Laboratory for Plant Diversity and Biogeography of East Asia, Kunming Institute of Botany, Chinese Academy of Sciences, Kunming, Yunnan, China

${ }^{2}$ University of Chinese Academy of Sciences, Beijing 100049, China

${ }^{3}$ East and Central Asia Regional Office, World Agroforestry Centre (ICRAF), Kunming, Yunnan, China

${ }^{4}$ Centre for Mountain Ecosystem Studies (CMES), Kunming Institute of Botany, Kunming, Yunnan, China

${ }^{5}$ Center of Excellence in Fungal Research, Mae Fah Luang University, Chiang Rai, Thailand

Luangharn T, Karunarathna SC, Mortimer PE, Hyde KD, Xu J 2019 - Morphological and molecular identification of Panus conchatus (Polyporaceae, Polyporales) from Yunnan Province, China. Studies in Fungi 4(1), 253-262, Doi 10.5943/sif/4/1/27

\begin{abstract}
Panus conchatus is a species of lentinoid fungi in the family Polyporaceae. This species is characterized by its concave, smooth, deeply decurrent gills, with distinctive purple grey to greyish magenta basidiocarps. This fungus is widely distributed in both tropical and temperate regions. Here, we report a specimen of $P$. conchatus collected from a temperate region in Yunnan Province, China. The specimen is described and illustrated based on macro- and micro-morphological characteristics. Phylogenetic analyses were done based on the sequence data of ITS and LSU, and the placement of the taxon was confirmed. This is the first time $P$. conchatus has been reported with molecular phylogenetic data from China. Full description, illustrations, color photographs, and a phylogenetic tree to show the placement of $P$. conchatus are provided.
\end{abstract}

Keywords - agaricoid form - hymenophoral trama - lentinoid mushroom - polyporales

\section{Introduction}

Mushrooms in the genus Panus are regarded as free gilled and form a monopyletic clade with Lentinus and Polyporus (Hussein et al. 2014). The genus Panus Fr. was introduced by Fries (1838), with $P$. conchatus as the type species (Fries 1838). Panus is an agaricoid genus that was introduced as a distinct lentinoid fungus in the order Polyporales (Senthilarasu 2014) and is considered as a subgenus of Lentinus (Pegler 1983(. Panus species are characterized by free gills; strongly radiate hymenophoral trama; somewhat leathery, often dimitic hyphae; abundant skeletal hyphae (typically unbranched); and a lack of hyphal pegs (Hard 1908, Hibbett et al. 1993, Hussein et al. 2014, Senthilarasu 2014).

Various authors have also identified different Panus and Lentinus morphological characteristics (Corner 1981, Thorn et al. 2000, Moncalvo et al. 2000, Drechsler-Santos et al. 2012). However, Panus is clearly distinguished by the presence of the hyphal system, in particular the thick-walled skeletal hyphae with unbranched or ligative hyphae in the context (Corner 1981), and its gills are also more thin and smooth edged than Lentinus (Hard 1908). 
Panus is regarded inappropriately as a food source (Vargas-Isla et al. 2015), while some Panus species, such as $P$. conchatus, $P$. crinitus, $P$. lecomtei, $P$. rudis, and $P$. strigellus are generally regarded as edible mushrooms by people in Brazil, Colombia and other countries in South America (Hard 1908, Fidalgo \& Prance 1976, Vargas-Isla et al. 2015). Panus is also a laccase fungal group, and contains a wide range of bioactive compounds as well as panepoxydone, panutorulon A, naematolin, and naematolon (Zjawion 2004, Zaidman et al. 2005, Ding et al. 2018). These compounds are used in natural remedies to cure various pathological diseases, such as cancers and cardiovascular diseases, and they possess hepatoprotective, antibacterial, antioxidant, and antiviral properties (Soares et al. 2013). Panus are used in a wide range of applications, including as white laccate fungi for pulp bleaching; in water treatment; and in the removal of phenols in the food industry (Zhou et al. 2014). The panepoxydone derived from $P$. conchatus and $P$. rudis is also known to inhibit NF- $\kappa$ B-mediated signal transduction in animal cells (Zjawion 2004).

The 231 taxa of Panus are listed in Index Fungorum (Accessed date: 15 August 2019) and 206 taxa are listed in MycoBank (MycoBank 2019; accessed date: 15 August 2019). Panus species are regarded as white rot fungi (Zhou et al. 2016), and are usually widely distributed in sub-tropical to tropical, temperate, and boreal regions in proximity to a wide range of broadleaf trees (Pegler 1975, 1983, Corner 1981, Vargas-Isla et al. 2015). Two Panus species in particular, P. conchatus and $P$. lecomtei, are distributed in tropical areas and irradiated in temperate regions (Zmitrovich et al. 2018).

Panus conchatus (Bull.) Fr. was introduced as Agaricus conchatus Bull. based on laterally, smooth, and usually pale purple to purple-brown upper surface to the entire margin (Senthilarasu 2014). This fungus has been reported as a common species distributed worldwide (Senthilarasu 2014, Zmitrovich et al. 2018). Ding et al. (2018) reported P. conchatus to be distributed in Henan, Jilin, Shaanxi, and Yunnan, China, but the findings were published without taxonomic and phylogenetic evidence. In this study, we introduce $P$. conchatus from Yunnan Province, China with color photographs, macro- and micro-morphological descriptions, and a phylogenetic tree to show the placement of the taxon.

\section{Material and Methods}

\section{Sample collection and isolation}

The basidiocarps were collected from a logwood of Pinus kesiya (Royle.) at the Kunming Institute of Botany, Yunnan Province, China, in December 2017. The internal tissues of the basidiocarps were placed on potato dextrose agar (PDA) under aseptic conditions to get a pure culture and incubated at $25^{\circ} \mathrm{C}$ for 14 days (Luangharn et al. 2017). Pure culture was deposited in the culture collection of the Kunming Institute of Botany (KUMCC) with the voucher number KUMCC18-0047. The cultures were maintained at $4^{\circ} \mathrm{C}$ for further study. The specimens were hot air dried at $40^{\circ} \mathrm{C}$ for 2 days and covered with wax paper containing dehydrated silica gel as a desiccant to control humidity. The herbarium specimens were deposited in the Herbarium of Kunming Institute of Botany, Academia Sinica (HKAS), Chinese Academy of Science, Yunnan Province, China, with the voucher number HKAS 97487.

\section{Morphological study}

Macro-morphological characteristics were obtained from fresh specimens following the methods previously described by Lodge et al. (2004) and Largent (1986). Color codes were recorded following (Ridgeway 1912). Microscopic characteristics were observed under an OLYMPUS SZ61 stereo microscope, with dried materials rehydrated in Congo red and 5\% $\mathrm{KOH}$. Micro-morphological characteristics were observed under a Nikon ECLIPSE Ni (Nikon, Tokyo, Japan) compound microscope objective lenses of $10 \times, 20 \times, 40 \times$ and $100 \times$. Photographs were taken with a Canon EOS 600D (Tokyo, Japan) digital camera fitted to the microscope. Measurements were taken using Tarosoft ${ }^{\circledR}$ Image Framework program v. 0.9.0.7. The size and shape of 
basidiospores followed Miettinen \& Larsson (2006) with a minimum of 50 basidiospore measurements from each basidiocarp. The photographs and drawing plates were edited in Adobe Photoshop CS3.

\section{DNA extraction, polymerase chain reaction (PCR), and sequencing}

Fungal mycelia were grown on PDA media; after incubation at $25^{\circ} \mathrm{C}$ for 2 weeks, fungal mycelia were scraped off and transferred into $1.5 \mathrm{ml}$ sterile tubes for DNA extraction. The Biospin Fungus Genomic DNA Extraction Kit $\left(\right.$ BioFlux $^{\circledR}$ ) was used to extract DNA, following the manufacturer's instructions. PCR amplifications were performed in a total volume of $25 \mu \mathrm{L}$ of PCR mixtures containing $9.5 \mu \mathrm{L}$ of $\mathrm{ddH}_{2} \mathrm{O}, 12.5 \mu \mathrm{L}$ of PCR master mix, $1 \mu \mathrm{L}$ of DNA sample, and $1 \mu \mathrm{L}$ of each primer. PCR amplification was carried out using primers LROR/LR5 for the nuclear ribosomal large subunit 28S rDNA gene (LSU) (Vilgalys \& Hester 1990), and ITS5/ITS4 for the internal transcribed spacer rDNA region (ITS1, 5.8S rDNA and ITS2) (White et al. 1990). PCR amplification for ITS was performed as follows: initial denaturation at $94^{\circ} \mathrm{C}$ for $3 \mathrm{~min}$, followed by 35 cycles at $95^{\circ} \mathrm{C}$ for $30 \mathrm{~s}, 55^{\circ} \mathrm{C}$ for $1 \mathrm{~min}, 72^{\circ} \mathrm{C}$ for $1 \mathrm{~min}$, and a final extension of $72^{\circ} \mathrm{C}$ for 10 min. PCR amplification for LSU was performed as follows: initial denaturation at $94^{\circ} \mathrm{C}$ for $3 \mathrm{~min}$, followed by 35 cycles at $94^{\circ} \mathrm{C}$ for $35 \mathrm{~s}, 55^{\circ} \mathrm{C}$ for $50 \mathrm{~s}, 72^{\circ} \mathrm{C}$ for $1 \mathrm{~min}$, and a final extension of $72^{\circ} \mathrm{C}$ for $10 \mathrm{~min}$. The sequencing of PCR products was carried out by Sangon Biotech (Shanghai) Co. Ltd. in China. The nucleotide sequence data acquired was deposited in GenBank to obtain the accession numbers.

\section{Phylogenetic analyses}

A total of 36 taxa included in the phylogenetic analyses retrieved from GenBank based on recent publications are shown in Table 1 . Sequences of closely related strains were retrieved based on BLAST search results in GenBank (http://www.ncbi.nlm.nih.gov). Single sequence alignment was generated with online sequence alignment tools MAFFT v. 7.394 (https://mafft.cbrc.jp/alignment/software/) (Katoh \& Standley 2013) and manually edited in BioEdit v. 7.0.9 (Hall 1999) and Clustal X (Thompson et al. 1997). To confirm the phylogenetic positions of fungal species, sequences of ITS and LSU were combined and analyzed with Maximum likelihood (ML), Maximum parsimony (MP), and Bayesian inference posterior probabilities (PP). The alignments were checked visually and improved manually where necessary, and gaps were treated as missing data.

Maximum likelihood phylogenetic analysis was performed using RAxML v. 7.2.6 (Stamatakis 2006) on the RAxML-HPC2 on XSEDE (v. 8.2.8) of the CIPRES science Gateway (https://www.phylo.org) (Miller et al. 2010), and a duplication was carried out using raxmlGUI v.0.9b2 (Silvestro \& Michalak 2010) with default parameters and 1000 bootstrap replicates. The final tree was selected from among suboptimal trees by comparing likelihood scores under the GTRGAMMA substitution model.

For Bayesian Inference (BI) analyses, best models of evolution were estimated by using MrModeltest 2.3 (Nylander 2004), and the Bayesian posterior probabilities (PP) were estimated by Markov Chain Monte Carlo sampling (MCMC) in MrBayes v. 3.2.2 ) Huelsenbeck \& Ronquist 2001(. Six simultaneous Markov chains were run for 1 million generations and trees were sampled every 100 generations; thus 10,000 trees were obtained. The suitable burn-in phases were determined by traces inspected in Tracer version 1.6 (Rambaut et al. 2014). Based on the tracer analysis, the first 2,000 trees, representing $20 \%$ of the burn-in phase of the analyses, were discarded, while the remaining trees were used for calculating posterior probabilities in the majority rule consensus tree. Maximum parsimony (MP) analyses were made using PAUP v. 4.0b10 (Swofford 2002). Trees were inferred using the heuristic search with random addition of sequences with 1000 replicates.

The resulting trees and data files were viewed in FigTree v. 1.4 program (Rambaut \& Drummond 2008) and edited using Microsoft Office PowerPoint 2010 and Adobe Illustrator CS3 (Adobe Systems Inc., USA). MLBP and MPBP equal to or greater than 70\%, and PP equal to or 
greater than 0.90 on the nodes are considered as significantly supported. Since the topologies of ML, MP and Bayesian analyses are the same, the ML tree was selected to show the placement of the taxon.

Table 1 Taxa and their GenBank accession numbers used in the phylogenetic analyses of this study.

\begin{tabular}{|c|c|c|c|c|}
\hline \multirow[t]{2}{*}{ Fungal species } & \multirow[t]{2}{*}{ Voucher } & \multicolumn{2}{|c|}{ GenBank accession no. } & \multirow[t]{2}{*}{ References } \\
\hline & & ITS & LSU & \\
\hline Panus conchatus & $\begin{array}{l}\text { KUMCC } \\
\mathbf{1 8 - 0 0 4 7}\end{array}$ & MK192053 & MK333258 & This study \\
\hline P. conchatus & X1234 & JN710579 & - & Miettinen et al. 2012 \\
\hline P. conchatus & FLAS-F-60901 & MH016880 & - & GenBank \\
\hline P. conchatus & CLZhao 1535 & MG231759 & - & GenBank \\
\hline P. conchatus & 4314 & - & AY616003 & Hussein et al. 2014 \\
\hline P. conchatus & 6254 & - & AY616004 & Hussein et al. 2014 \\
\hline P. conchatus & LE265028 & KM41146 & KM434323 & Zmitrovich \& Kovalenko 2016 \\
\hline P. conchatus & JMH44 & KM267730 & - & Hussein et al. 2014 \\
\hline P. fulvus & LCF573 & - & AY615997 & GenBank \\
\hline P. fulvus & 10689 & - & AY615996 & GenBank \\
\hline P. lecomtei & TMIC35103 & JQ955726 & - & Vargas-Isla et al. 2015 \\
\hline P. lecomtei & HHB-11042-Sp & KP135328 & KP135233 & Floudas \& Hibbett 2015 \\
\hline P. lecomtei & HHB-9614 & KP135329 & - & Floudas \& Hibbett 2015 \\
\hline P. neostrigosus & LSPQ-NSM-106 & KU761234 & KU761114 & Dufresne et al. 2017 \\
\hline P. neostrigosus & LSPQ-NSM-107 & KU761235 & KU761115 & Dufresne et al. 2017 \\
\hline P. neostrigosus & LSPQ-NSM-108 & KU761236 & KU761118 & Dufresne et al. 2017 \\
\hline P. rudis & ZJ1005DKJ02 & KU863049 & - & GenBank \\
\hline P. rudis & ZJ1005DKJ03 & KU863050 & - & GenBank \\
\hline P. rudis & ZJ1005DKJ04 & KU863051 & - & GenBank \\
\hline P. similis & KWGM 39 & KY630517 & - & GenBank \\
\hline P. similis & DMC 189 & - & EU908182 & Douanla-Meli \& Langer 2010 \\
\hline P. similis & LE287548 & KM411466 & KM411482 & Zmitrovich \& Kovalenko 2016 \\
\hline P. strigellus & 9114 & - & AY616001 & GenBank \\
\hline P. strigellus & INPA239979 & JQ955724 & JQ955731 & GenBank \\
\hline P. strigellus & TENN55993 & JQ955728 & - & GenBank \\
\hline P. strigellus & TENN56192 & JQ955727 & - & GenBank \\
\hline P. strigellus & INPA222827 & JQ955722 & - & GenBank \\
\hline P. velutinus & NAL318 & - & GQ487335 & Douanla-Meli \& Langer 2010 \\
\hline P. velutinus & DMC 694 & - & EU908187 & Douanla-Meli \& Langer 2010 \\
\hline P. velutinus & DMC 695 & - & EU908188 & Douanla-Meli \& Langer 2010 \\
\hline Panus sp. & M85 & КР096364 & - & GenBank \\
\hline Panus sp. & MEL 2382698 & KP012877 & - & GenBank \\
\hline Panus sp. & MEL 2382967 & KР012827 & - & GenBank \\
\hline Polyporus melanopus & CIEFAP148 & AF516569 & - & GenBank \\
\hline P. conifericola & Cui9950 & KU189783 & - & Zhou et al. 2016 \\
\hline
\end{tabular}

\section{Results}

\section{Phylogenetic analyses}

The sequence dataset comprises 23 ITS and 17 LSU from 35 samples and includes 33 ingroup taxa and 2 outgroup taxa (Polyporus melanopus CIEFAP 148 and P. conifericola Cui 9950 ) (Table 1). The dataset had an aligned length of 1,487 total characters, of which 1,164 were constant, while 246 variable characters were parsimony-informative, and 77 characters were parsimony-uninformative. The ML analyses carried out from RAxML and raxmlGUI analyses 
provided similar results, and the topology of the ML tree was similar to that of the PP tree. Here, only RAxML ML tree topologies were chosen, and they are shown in Figure 1. Nine Panus species used in this study were grouped together MLBS $=100 \% / \mathrm{MPBS}=100 \% / \mathrm{PP}=1.00$, and segregated into two main clades. Tree topologies of our study were similar to that of Hussein et al. (2014). In the phylogenetic tree, seven clades were seen, of which six were Panus species; including $P$. conchatus, $P$. fulvus, $P$. lecomtei, $P$. rudis, $P$. strigellus, $P$. velutinus, and one outgroup clade. Phylogenetic analyses showed considerably high support for the $P$. conchatus strain KUMCC18-0047 with MLBS = 92\%/ MPBS=90\%/ PP = 0.98.

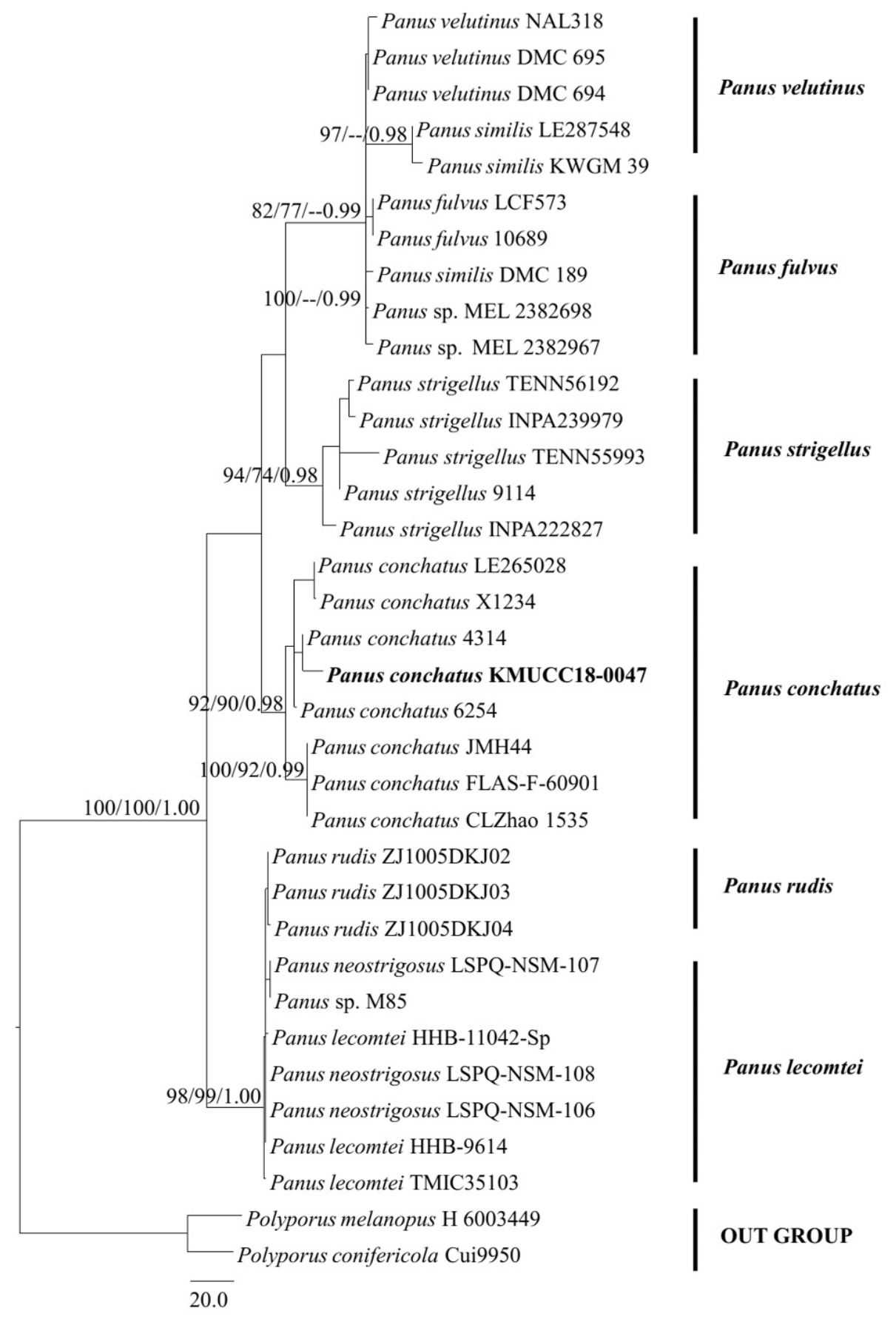

Fig. 1 - RAxML tree based on a combined sequence dataset of ITS and LSU. Bootstrap values for ML and MP are equal to or greater than $70 \%$, and PP equal or greater than 0.90 are defined as ML/MP/PP. The tree is rooted with Polyporus melanopus H6003449 and P. conifericola Cui9950. Newly recorded species are indicated in black bold. 


\section{Taxonomy analyses}

Panus conchatus (Bull.) Fr., Epicr. syst. mycol. (Upsaliae): 396. 1838.

Fig. 2

Facesoffungi number: FoF 05597

Basidiocarps concave, relatively small to medium-sized. Pileus shape $1.5-4.5 \mathrm{~cm}$ in diameter, initially lateral and reduced, some lateral when mature, usually single when pinhead, slightly to lateral with substantial, overlap expand from base when immature to mature, depressed at center, moderate to deeply indent in side-view when mature, smooth and slippery when wet, soft from center toward margin, sticky at base when fresh, and brittle when dried. Pileus surface color variable, initially pinkish (13A2) when young, pale pinkish (13A2), with fading to greyish red (11D4), purple grey (13B2), greyish magenta (13C4), slightly greyish red (11C6), darker toward margin, light orange (5A4) at center, and reddish brown (9E7) when dried, rose (12A4) to bluish red (12A6) on bruising. Pileus texture pubescent with netted when young, and usually thin with silky. Pileus margin incurved, purple grey (13B2). Lamellae sub-distant, deeply decurrentes lines, become forking and anastomosing (joining crossways) at base, usually orange white (6A2), light orange (6A4), yellowish red (8B7), brownish red (8C8) at center toward the base when mature to old, pinkish (13A2), purple grey (13B2-13D2), reddish grey (12B2) toward pileus margin, and greyish ruby (12C3-12E4) when dried. Stipe sessile, 0.5-1.7 mm, scaly, with white (13A1) cottony, tough, downy, and strongly attached to the substrate.

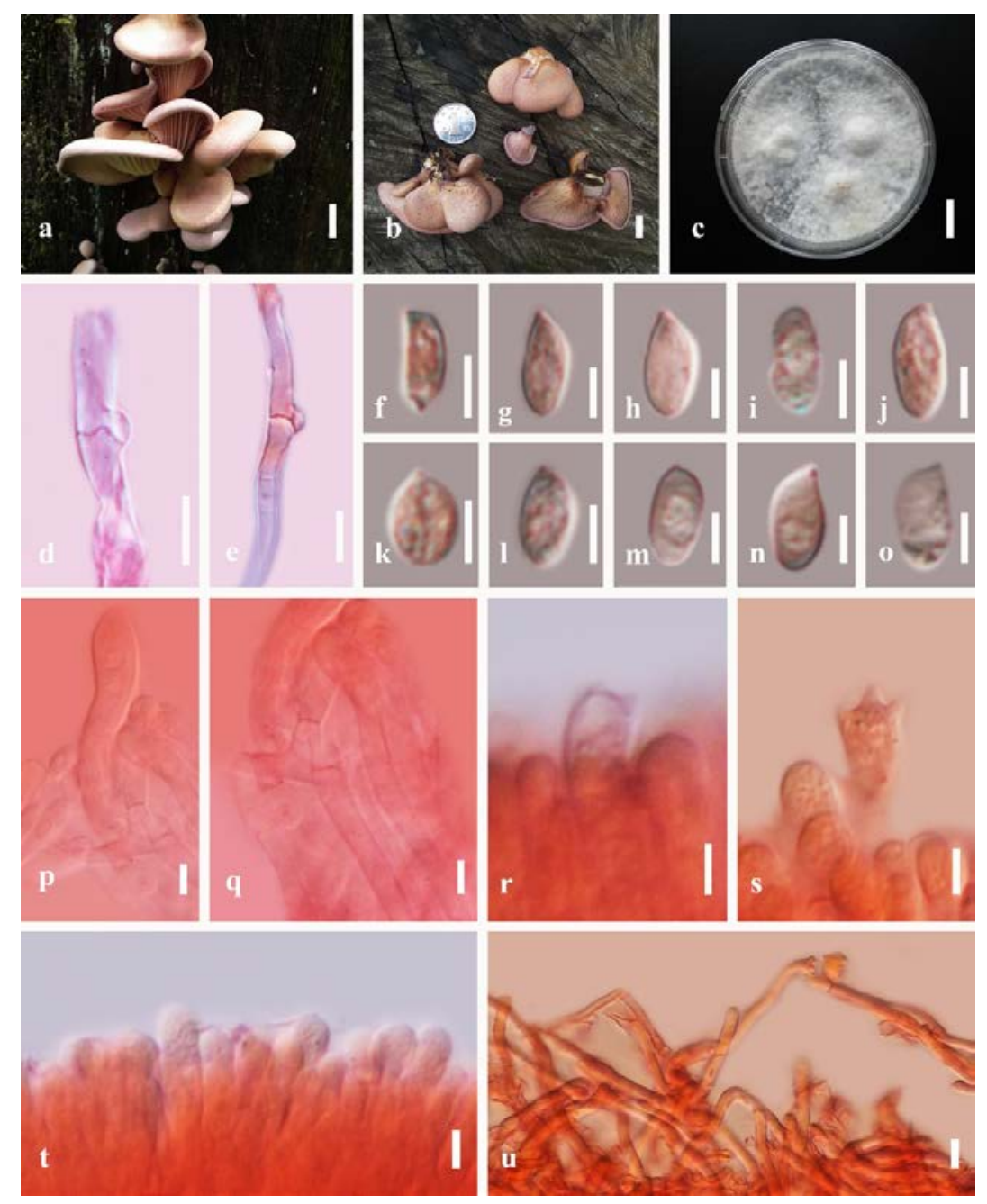

Fig. 2 - Morphological characteristics of Panus conchatus strain KUMCC 18-0047. $\mathrm{a}-\mathrm{b}$ basidiocarps. c the fungal culture incubated at $25^{\circ} \mathrm{C}$ for 18 days. d-e clamp connection. $\mathrm{f}-\mathrm{o}$ basidiospores. $\mathrm{p}-\mathrm{q}$ cheilocystidia. $\mathrm{r}-\mathrm{s}$ basidia. $\mathrm{t}$ metuloids and subhymenium. $\mathrm{u}$ generative hyphae. Scale bar: $\mathrm{a}-\mathrm{c}=1 \mathrm{~cm}, \mathrm{~d}-\mathrm{e}, \mathrm{p}-\mathrm{t}=5 \mu \mathrm{m}, \mathrm{f}-\mathrm{o}=2 \mu \mathrm{m}, \mathrm{u}=10 \mu \mathrm{m}$. 
Hyphal system: hymenophore - white (13A1) to yellowish white (4A2), soft and cottony. Context dense context layer, up to 2.7-4.3 $\mu \mathrm{m}$ diameter, white to purple grey (13B2) close to the base, mostly generative hyphae, thin-walled with clamp connections, colorless, simple septa, much branched, with a few branches in the distal end, and thick near the base, and lack of skeletal hyphae. Pileipellis structure cutis, trichoderm to intricate trichoderm. Basidia narrow clavate, with 4 sterigmata, 3.6-4.2 $\times 22.5-32.3 \mu \mathrm{m}(\bar{x}=30)$. Basidiospores mostly oblong to sub-cylindrical, $(1.6-) 2.4-3.0-3.4(-3.6) \times(3.6-) 5.2-6.2-7.4(-7.5) \mu \mathrm{m}(\bar{x}=2.7 \times 5.9 \mu \mathrm{m}, n=50)$, ellipsoid (1.9)2.8-3.2-4.0(-4.2) × (3.8-)5.2-6.3-7.5(-7.6) $\mu \mathrm{m}(\bar{x}=3.3 \times 6.2 \mu \mathrm{m}, n=50)$, and subglobose (2.2)2.7-3.1-3.4(-4.0) × (2.7-)2.9-3.5-4.7(-5.4) $\mu \mathrm{m}(\bar{x}=3.0 \times 3.5 \mu \mathrm{m}, n=50)$, white (11A1), overlaid by a hyaline, with thin-walled when maturity, usually occurred suprahilar depression with a distinct hilar appendage. Lamellae $1.8-3.5 \mathrm{~mm}$ in width, generative hyphae, hyaline with clamp connections are prominent, 2.7-4.2 $\mu \mathrm{m}$ in width $(\bar{x}=30)$; skeletal hyphae, hyaline, thin walled, metuloids abundant to occasional on edges of the lamellae, and broad rounded apex of metuloids.

Culture characteristics - initially produced thin white (13A1) mycelium and covered the media surface after incubation for 10 days, and tightly, scattered cottony after incubated 18 days.

Known distribution - widespread in temperate regions.

Additional material examined - CHINA, Yunnan Province, Kunming Botanical Garden, Kunming Institute of Botany, solitary on logwood of Pinus kesiya (Royle.) species, $25^{\circ} 07^{\prime} 58^{\prime} \mathrm{N}, 102^{\circ} 44^{\prime} 39^{\prime} \mathrm{E}$, on December 2017 , T. Luangharn, herbarium number HKAS 97487 , culture number KUMCC 18-0047

\section{Discussion}

Panus conchatus has previously been described in Yunnan Province, China though the descriptions were based only on morphology and not phylogeny. Few studies on the biologically active compounds of $P$. conchatus have been conducted (Ding et al. 2018). In this study, $P$. conchatus collected from the logwood of Pinus kesiya in the temperate climate of Kunming is described based on both morphology and phylogeny. Our collection is in accordance with Pegler (1983), which mentions that $P$. conchatus is often overlapping in a wide range of temperate regions. $P$. conchatus is also widely distributed on hardwoods in subtropical to tropical regions, especially in all types of tropical forests (Corner 1981), including in America and Cameroon (Douanla-Meli 2007). The Panus species is also associated with Betula spp. and Populus spp. in Russia (Zmitrovich et al. 2018).

Our specimen of P. conchatus was smaller than the type material described by Corner (1981), which exhibited smaller lamellae with deeply decurrent lines. Panus conchatus basidiocarp development are usually occurs as an ephemeral partial veil, and obliterates during basidiocarp expansion (Zmitrovich et al. 2018). We then compared our $P$. conchatus sample with similar species and found that our specimen has some unique differences. The details of the macro-and microcharacteristics are compiled in Table 2. In addition, our results strongly support Pegler (1983), who mentions that this fungus could be distributed in temperate regions.

Few studies have evaluated the phylogeny of Panus species without illustrated taxonomy (Moreno et al. 2011, Sotome et al. 2011, Miettinen et al. 2012, Hussein et al. 2014, Zmitrovich \& Kovalenko 2016). This study lacks a number of Panus collections from China to compare with our collection. Our phylogeny analyses were carried out with combined genes of nLSU and ITS rDNA, while our sequences of TEF1 (MK341057) and RPB2 (MK341058) were added to GenBank (however, they were not included in our analysis, since RPB2 and TEF1 sequences of Panus are not available in GenBank). The results revealed that our collection groups of $P$. conchatus collected from China and Tanzania (Hussein et al. 2014, Zmitrovich \& Kovalenko 2016) had high supports (ML=92\%, MP=90\%, $\mathrm{PP}=0.99 \%$ ). The clade of $P$. fulvus, $P$. strigellus, and $P$. velutinus serve as a sister group to the $P$. conchatus clade. These results are similar to Hussein et al. (2014), who showed that $P$. conchatus was grouped in the $P$. strigellus clade; however, this fungus has also been reported to form a monopyletic clade with Lentinus and Polyporus (Hussein et al. 2014). The results of this study will be helpful for the database of Yunnan Panus. In this study, we identified 
P. conchatus from Yunnan Province, China based on morphological characteristics together with phylogenetic data.

Table 2 The comparison of macro- and micro- characteristics of Panus conchatus specimen collected in this study with the type species.

\begin{tabular}{|c|c|c|}
\hline Macro-characteristics & $\begin{array}{l}\text { P. conchatus } \\
\text { (Corner 1981) }\end{array}$ & $\begin{array}{l}\text { P. conchatus } \\
\text { KUMCC18-0047 }\end{array}$ \\
\hline Basidiocarps & $2-8 \mathrm{~cm}$ in width & $1-5 \mathrm{~cm}$ in width \\
\hline Basidiocarp shape & concave or plano-infundibuliform & concave \\
\hline Basidiocarp color & pale lilac-magenta & $\begin{array}{l}\text { greyish red (11D5), purple grey } \\
\text { (13B2) to greyish magenta (13C4) }\end{array}$ \\
\hline Basidiocarp surface & smooth when wet & $\begin{array}{l}\text { silky and soft when young to } \\
\text { mature }\end{array}$ \\
\hline Margin & entire or slightly incurved & incurved \\
\hline Stipe & short $(\sim 6 \mathrm{~cm})$ with irregular & sessile or short \\
\hline Lamellae size & 3.0-3.5 $\mathrm{mm}$ in width, and $4-5$ ranks & $1.8-3.5 \mathrm{~mm}$ in width \\
\hline Lamellae color & $\begin{array}{l}\text { dingy cream to pale ochraceous, } \\
\text { pinkish near the entire edge }\end{array}$ & $\begin{array}{l}\text { reddish grey (12B2), orange white } \\
\text { (6A2), brownish red (8C8), and } \\
\text { pinkish (13A2) to purple grey } \\
\text { (13B2-13D2) when mature }\end{array}$ \\
\hline $\begin{array}{l}\text { Lamellae shape and } \\
\text { surface }\end{array}$ & $\begin{array}{l}\text { deeply decurrent, abundant of } \\
\text { metuloids, rather crowded, white } \\
\text { thin, soft and coriaceous when fresh }\end{array}$ & $\begin{array}{l}\text { deeply decurrent lines with soft } \\
\text { surface }\end{array}$ \\
\hline \multicolumn{3}{|l|}{ Micro-characteristics } \\
\hline Hyphal system & No report & $\begin{array}{l}\text { generative hyphae thin walled, with } \\
2.70-4.20 \mu \mathrm{m} \text { in width, with clamp } \\
\text { connections, hyaline, and somewhat } \\
\text { abundant thick-walled metuloids }\end{array}$ \\
\hline $\begin{array}{l}\text { Basidiospore shape and } \\
\text { size }\end{array}$ & $\begin{array}{l}\text { the shape is not mention, } \\
3.0-3.5 \times 6.0-7.0 \mu \mathrm{m}\end{array}$ & $\begin{array}{l}\text { oblong to sub-cylindrical } \\
(2.65 \times 5.94 \mu \mathrm{m}) \\
\text { ellipsoid }(3.30 \times 6.19 \mu \mathrm{m}) \\
\text { and subglobose } \\
(3.03 \times 3.49 \mu \mathrm{m})\end{array}$ \\
\hline Basidia shape & no report & narrow clavate \\
\hline Basidia size & $\begin{array}{l}5.0-6.0 \times 20.0-28.0 \mu \mathrm{m}, \\
\text { with } 4 \text { sterigmata }\end{array}$ & $\begin{array}{l}3.61-4.21 \times 22.45-32.25 \mu \mathrm{m}(\bar{x}= \\
\text { 30), with } 4 \text { sterigmata }\end{array}$ \\
\hline
\end{tabular}

\section{Acknowledgements}

We appreciate the kind support given by the Key Laboratory for Plant Diversity and Biogeography of East Asia, Kunming Institute of Botany, Chinese Academy of Sciences, Kunming 650201, Yunnan Province, China. We thank the Germplasm Bank of Wild Species, Kunming Institute of Botany, Kunming 650201, Yunnan, China for enabling our molecular phylogenetic work.

\section{References}

Corner EJH. 1981 - The agaric genera Lentinus, Panus, and Pleurotus with particular reference to Malaysian species. Nova Hedwigia 69, 1-169.

Ding JH, Li ZH, Feng T, Liu JK. 2018 - A new cadinane sesquiterpenoid from cultures of the basidiomycete Panus conchatus. Natural Product Research 32, 2333-2337.

Douanla-Meli C. 2007 - Fungi of Cameroon, ecological diversity with emphasis on the taxonomy of non-gilled Hymenomycetes from the Mbalmayo forest reserve. Bibliotheca Mycologica 21, 202-412. 
Douanla-Meli C, Langer EJ. 2010 - Reassessment of phylogenetic relationships of some lentinoid fungi with velutinate basidiomes based on partial 28S ribosomal RNA gene sequencing. Sydowia 62, 23-35.

Drechsler-Santos ER, Wartchow F, Coimbra VRM, Gibertoni TB, Cavalcanti AQ. 2012 - Studies on lentinoid fungi (Lentinus and Panus) from the semi-arid region of Brazil. Journal of the Torrey Botanical Society 139, 437-446.

Dufresne PJ, Moonjely SS, Ozaki K, Tremblay C et al. 2017 - High frequency of pathogenic Aspergillus species among nonsporulating moulds from respiratory tract samples. Medical Mycology 55, 233-236.

Fidalgo O, Prance GT. 1976 - The ethnomycology of the Sanama Indians. Mycologia 68, 201-210.

Floudas D, Hibbett DS. 2015 - Revisiting the taxonomy of Phanerochaete (Polyporales, Basidiomycota) using a four gene dataset and extensive ITS sampling. Fungal Biology 119, 679-719.

Fries E. 1838 - Epicrisis systematis. Mycologici, pp. 398.

Hall TA. 1999 - BioEdit: a user-friendly biological sequence alignment editor and analysis program for Windows 95/98/NT. Nucleic Acids Symposium Series 41, 95-98.

Hard ML. 1908 - The mushroom, edible and otherwise its habitat and its time of growth. Columbus, Ohio, pp. 222-226.

Hibbett DS, Murakami S, Tsuneda A. 1993 - Sporocarp ontogeny in Panus (Basidiomycotina): evolution and classification. American Journal of Botany 80, 1336-1348.

Huelsenbeck JP, Ronquist F. 2001 - MRBAYES: Bayesian inference of phylogenetic trees. Bioinformatics 17, 754-755.

Hussein JM, Tibuhwa DD, Mshandete AM, Kivaisi AK. 2014 - Molecular phylogeny of saprophytic wild edible mushroom species from Tanzania based on ITS and nLSU rDNA sequences. Current Research in Environmental \& Applied Mycology 4, 250-260.

Katoh K, Standley K. 2013 - MAFFT multiple sequence alignment software version 7: improvements in performance and usability. Molecular Biology and Evolution 30, 772-780.

Largent DL. 1986 - How to identify mushrooms to genus. CA USA: Mad River Press.

Lodge DJ, Ammirati FJ, O’Dell TE, Mueller GM. 2004 - Collecting and describing macrofungi. In: Mueller GM, Bills GF, Foster MS. (eds), Biodiversity of fungi inventory and monitoring methods. Elsevier Academic Press, London, pp. 128-154.

Luangharn T, Karunarathna SC, Khan S, Xu J et al. 2017 - Antibacterial activity, optimal culture conditions and cultivation of the medicinal Ganoderma australe, new to Thailand. Mycosphere 8, 1108-1123.

Miettinen O, Larsson KH. 2006 - Trechispora elongata species nova from North Europe. Mycotaxon 96, 193-198.

Miettinen O, Larsson E, Sjökvist E, Larsson KH. 2012 - Comprehensive taxon sampling reveals unaccounted diversity and morphological plasticity in a group of dimitic polypores (Polyporales, Basidiomycota). Cladistics 28, 251-270.

Miller MA, Pfeiffer W, Schwartz T. 2010 - Creating the CIPRES Science Gateway for inference of large phylogenetic trees; Proceedings of the Gateway Computing Environments Workshop (GCE). Institute of Electrical and Electronics Engineers, Louisiana, 1-8.

Moncalvo JM, Lutzoni FM, Rehner SA, Johnson J, Vilgalys R. 2000 - Phylogenetic relationships of agaric fungi based on nuclear large subunit ribosomal sequences. Systematic Biology 49, 278-305.

Moreno G, Blanco MN, Checa J, Platas G, Peláez F. 2011 - Taxonomic and phylogenetic revision of three rare irpicoid species within the Meruliaceae. Mycological Progress 10, 481-491.

Nylander JAA. 2004 - MrModeltest 2.0. program distributed by the author. Evolutionary Biology Centre. Uppsala University.

Pegler DN. 1975 - The classification of the genus Lentinus Fr. (Basidiomycota). Kavaka 3, 11-20.

Pegler DN. 1983 - The genus Lentinus: a world monograph. Kew Bulletin, Additional Series 10, $1-281$. 
Rambaut A, Drummond A. 2008 - FigTree: Tree figure drawing tool, version 12. - Institute of Evolutionary Biology, University of Edinburgh.

Rambaut A, Suchard MA, Xie D, Drummond AJ. 2014 - Tracer v. $16 . \quad-$ http://beast.bio.ed.ac.uk/Tracer (accessed 10 May 2019).

Ridgeway R. 1912 - Color standards and color nomenclature. Washington DC, US. Ridgeway.

Senthilarasu G. 2014 - Diversity of agarics (gilled mushrooms) of Maharashtra, India. Current Research in Environmental \& Applied Mycology 4, 58-78.

Silvestro D, Michalak I. 2010 - raxmlGUI: a graphical front-end for RAxML Program and documentation. http://www.sourceforge.com (accessed 10 May 2019).

Soares AA, de Sá-Nakanishi AB, Bracht A, Da costa SMG. 2013 - Hepatoprotective effects of mushrooms. Molecule 18, 7630.

Sotome K, Hattori T, Ota Y. 2011 - Taxonomic study on a threatened polypore, Polyporus pseudobetulinus, and a morphologically similar species, $P$. subvarius. Mycoscience 52, 319326.

Stamatakis A. 2006 - RAXML-VI-HPC: maximum likelihood-based phylogenetic analyses with thousands of taxa and mixed models. Bioinformatics 22, 2688-2690.

Swofford DL. 2002 - PAUP*. Phylogenetic analysis using parsimony (*and Other Methods), Version 4.0 beta version. Sinauer Associates, Sunderland.

Thompson JD, Gibson TJ, Plewniak F, Jeanmougin F, Higgins DG. 1997 - The CLUSTAL X windows interface: flexible strategies for multiple sequence alignment aided by quality analysis tools. Nucleic Acids Research 25, 4876-4882.

Thorn RG, Moncalvo JM, Reddy CA, Vilgalys R. 2000 - Phylogenetic analyses and the distribution of nematophagy support a monophyletic Pleurotaceae within the polyphyletic pleurotoid lentinoid fungi. Mycologia 92, 241-252.

Vargas-Isla R, Capelari M, Menolli Jr. N, Nagasawa E et al. 2015 - Relationship between Panus lecomtei and $P$. strigellus inferred from their morphological, molecular and biological characteristics. Mycoscience 56, 561-571.

Vilgalys R, Hester M. 1990 - Rapid genetic identification and mapping of enzymatically amplified ribosomal DNA from several Cryptococcus species. Journal of Bacteriology 172, 4239-4246.

White TJ, Bruns T, Lee SJ, Taylor JW. 1990 - Amplification and direct sequencing of fungal ribosomal RNA genes for phylogenetics. PCR protocols: a guide to methods and applications 18, 315-322.

Zaidman B, Yassin M, Mahajana J, Wasser SP. 2005 - Medicinal mushroom modulators of molecular targets as cancer therapeutics. Applied Microbiology and Biotechnology 67, 453468.

Zhou P, Fu C, Fu S, Zhan H. 2014 - Purification and characterization of white laccase from the white rot fungus Panus conchatus. Bioresources 9, 1964-1976.

Zhou JL, Zhu L, Chen H, Cui BK. 2016 - Taxonomy and phylogeny of Polyporus group Melanopus (Polyporales, Basidiomycota) from China. PLoS ONE 11, 1-23.

Zjawion JK. 2004 - Biologically active compounds from Aphyllophorales (Polypore) fungi. Journal of Natural Products 67, 300-310.

Zmitrovich I, Kovalenko A. 2016 - Lentinoid and polyporoid fungi, two generic conglomerates containing important medicinal mushrooms in molecular perspective. International Journal of Medicinal Mushrooms 18, 23-38.

Zmitrovich IV, Bondartseva MA, Perevedentseva LG, Myasnikov AG, Kovalenko AE. 2018 - The Meruliaceae of Russia. II. Panus. Turczaninowia 21, 29-44. 